\title{
Lixiviação de poligalacturonases obtidas pela fermentação semissólida da casca e albedo do maracujá-amarelo
}

\author{
Carlos A. B. de Sousa ${ }^{1}$, Flávio L. H. da Silva² \& Líbia de S. Conrado ${ }^{3}$
}

RESUMO

Obtiveram-se poligalacturonases por fermentação semissólida usando-se, como substrato, o resíduo agroindustrial do maracujá-amarelo (Passiflora edulis flavicarpa) e, como agente da fermentação, o fungo filamentoso Aspergillus niger mutante CCT 0916. Para otimizar a etapa de recuperação das enzimas os parâmetros da lixiviação: agitação, tempo de contato e relação solvente/substrato, foram investigados em um planejamento experimental fatorial $2^{3}$. Agitação de $50 \mathrm{rpm}, 45 \mathrm{~min}$ e relação 10:1 proporcionaram a melhor recuperação de enzimas em que os resultados avaliados por meio da metodologia de superfície de resposta, mostraram que o resíduo do maracujá é um substrato adequado para a produção de poligalacturonases.

Palavras-chave: recuperação, extração, Aspergillus niger, resíduo agroindustrial

\section{Leaching of polygalacturonases produced by solid state fermentation of peel and albedo of passion fruit}

\section{ABSTRACT}

Polygalacturonases enzyme was produced by solid state fermentation using as substrate the residue of passion fruit (Passiflora edulis flavicarpa) and as fermentation agent the mutant fungus Aspergillus niger CCT 0916. To optimize the recovery step of the enzymes, the values of the leaching parameters such as agitation, contact time and solvent/substrate relation were investigated with factorial experimental design $2^{3}$. Agitation of $50 \mathrm{rpm}, 45 \mathrm{~min}$ and relation 10:1 provided the best recovery results. The response surface analysis, showed that the residue of passion fruit is an adequate substrate for the production of polygalacturonase enzyme.

Key words: recovery, extraction, Aspergillus niger, agro-industrial residue 


\section{INTRODUÇÃO}

As pectinases estão entre as enzimas mais utilizadas na indústria de alimentos, principalmente para a extração, clarificação e remoção de pectina de suco de frutas (Uenojo \& Pastore, 2007; Camargo et al., 2005; Alcântara et al., 2010). Dentre as pectinases utilizadas na indústria a poligalacturonase produzida por Aspergillus niger é uma das mais estudadas em virtude da sua elevada significância comercial (Ustok et al., 2007).

A produção de pectinases por fermentação semissólida (FSS) tem a vantagem de permitir a produção de enzimas brutas mais concentradas e, em consequência, com menores custos de extração e purificação (Santos et al., 2008a). Este processo tem, como principal característica, o crescimento de microorganismos sobre ou dentro de partículas de uma matriz sólida, em que a quantidade de líquido apresenta um nível de atividade de água que possa garantir o crescimento e metabolismo dos microorganismos mas não excede a máxima capacidade de ligação da água com a matriz sólida (Pinto et al., 2006).

Muitos resíduos agroindustriais podem ser utilizados em FSS (Silva et al., 2005) o que representa grande interesse econômico para regiões produtoras de biomassa e resíduos agroindustriais, que são materiais de baixo custo e abundantes. A eficiência do processo de extração das enzimas produzidas é um fator crítico para determinar a viabilidade econômica da FSS (Castilho et al., 2000).

Estudos realizados com a aplicação do resíduo agroindustrial (casca e albedo) do maracujá-amarelo (Passiflora edulis flavicarpa) em processos de FSS para produção de pectinases, têm demonstrado que esta pode ser uma aplicação bastante promissora uma vez que foram obtidos altos valores de atividade pectinolítica e poligalacturonásica (Pinto et al., 2006; Souza et al., 2010). Além disso, pode representar um destino adequado para o resíduo agroindustrial da cultura do maracujá que, no ano de 2007, teve uma produção de 664.286 toneladas de frutos, os quais geraram cerca de 405.214 toneladas de resíduo (Sousa, 2010).

Um dos aspectos mais significativos da fermentação semissólida é a adequada recuperação das biomoléculas produzidas no processo fermentativo. Uma etapa inicial da recuperação de enzimas obtidas por fermentação semissólida é a lixiviação do material fermentado, que consiste na dissolução preferencial de um ou vários solutos de interesse por meio do contato entre um sólido e um solvente líquido (Fernández, 2009).

Para o desenvolvimento de um processo de lixiviação eficiente existe, além da seleção do equipamento adequado, a influência de diferentes variáveis entre as quais se destacam a preparação dos sólidos, a relação solvente/massa, a temperatura do processo, o pH do solvente, a tensão superficial do líquido, o grau de agitação do sistema e a presença ou não de reação química na extração (Fernández, 2009). Além do mais, a extração das enzimas deve ser realizada em valores de temperatura e $\mathrm{pH}$ onde a estabilidade seja ótima e sua atividade biológica seja igualmente elevada, sem causar danos às biomoléculas ou ao solvente (Sousa, 2010).

O objetivo deste trabalho foi determinar os valores dos parâmetros da operação de lixiviação das enzimas produzidas pelo fungo Aspergillus niger mutante CCT 0916, no processo de fermentação semissólida de casca e albedo do maracujáamarelo (Passiflora edulis flavicarpa), que resultasse em máxima recuperação das enzimas presentes no meio fermentado. Os parâmetros analisados foram: influência da agitação do sistema; tempo de contato entre o solvente e o substrato fermentado e a relação volume de solvente/massa de substrato. Os resultados foram avaliados por meio da metodologia de superfície de resposta.

\section{Material E MÉTODOS}

A fermentação semissólida da casca do maracujá-amarelo foi conduzida de acordo com metodologia descrita na literatura, segundo as condições que resultam em máxima produção de poligalacturonases (Souza et al., 2010). Os parâmetros da fermentação foram: $40 \%$ de umidade no substrato, adição de fonte de nitrogênio $\left(\left(\mathrm{NH}_{4}\right)_{2} \mathrm{SO}_{4}\right)$ correspondente a $1 \%$ da massa total do meio semisssólido e inoculação de $10^{7}$ esporos de Aspergillus niger mutante CCT 0916 por grama de meio semissólido. A ativação dos esporos foi realizada conforme Couri \& Farias (1995). Os biorreatores consistiam de erlenmeyers plásticos de $250 \mathrm{~mL}$ de capacidade, contendo $10 \mathrm{~g}$ do substrato. Após esterilização do meio em autoclave e inoculação dos esporos, os biorreatores foram mantidos em estufa a $30 \pm 1{ }^{\circ} \mathrm{C}$, com reposição de umidade, durante $66 \mathrm{~h}$; decorrido este período tiveram início os ensaios de extração, segundo o planejamento.

O estudo da recuperação das enzimas presentes no meio semissólido fermentado seguiu um planejamento fatorial $2^{3}$ para a operação de lixiviação, com três repetições no ponto central, totalizando 11 ensaios. O planejamento teve, como variável dependente, a atividade poligalacturonásica (APG) e, como variáveis independentes, a agitação do meio (AG), o tempo de contato entre o solvente e o meio fermentado (TC) e a relação solvente/massa (RE).

O nível de significância para o estudo das condições de extração da enzima foi de $95 \%$ de confiança. Para validação dos modelos foi utilizada a análise de variância verificando-se o coeficiente de determinação $\left(R^{2}\right)$ e o teste $F$ através do programa Statistical 5.0.

Em cada erlenmeyer foi adicionado um volume de solvente tampão acetato de sódio $200 \mathrm{mM}$ de pH 4,5 (solvente), segundo o planejamento experimental, os quais foram transferidos para uma incubadora modelo Marconi MA 420, com temperatura estabilizada em $35 \pm 0,5^{\circ} \mathrm{C}$. Foram programados, no equipamento, a agitação (AG) e o tempo de contato entre o solvente e o meio fermentado (TC). Ao final do tempo programado para a lixiviação os erlenmeyers foram retirados da incubadora. Com o auxílio de filtros de algodão o extrato fermentado presente em cada erlenmeyer foi recolhido por filtração, resfriado a $\pm 4^{\circ} \mathrm{C}$ e centrifugado a $700 \mathrm{rpm}$ por $10 \mathrm{~min}$. $\mathrm{O}$ sobrenadante foi recolhido e analisado quanto à atividade poligalacturonásica.

A atividade da poligalacturonase (APG) foi estimada pela quantificação de substâncias redutoras liberadas de uma solução $0,25 \%(\mathrm{~m} / \mathrm{v})$ de ácido poligalacturônico em tampão acetato $200 \mathrm{mM} \mathrm{pH} 4,5$, depois de $30 \mathrm{~min}$ de incubação a $35^{\circ} \mathrm{C}$. 
Uma unidade de atividade poligalacturonásica foi definida como a quantidade de enzima que libera $1 \mu$ mol de ácido galacturônico por minuto, nas condições de reação (Santos et al., 2008b). Os resultados foram expressos em unidades de atividade recuperada por grama de meio úmido fermentado $\left(\mathrm{U} \mathrm{g}^{-1}\right)$.

\section{RESULTADOS E DISCUSSÃO}

A Tabela 1 apresenta os resultados de atividade das poligalacturonases recuperadas do meio fermentado nas condições de extração estudadas neste trabalho.

Tabela 1. Variação da atividade da poligalacturonase (APG) em função das condições de extração

\begin{tabular}{|c|c|c|c|c|}
\hline Ensaio & $\begin{array}{c}\mathrm{AG} \\
\text { (rpm) }\end{array}$ & $\begin{array}{c}\mathrm{TC} \\
(\mathrm{min})\end{array}$ & $\begin{array}{c}\mathrm{RE} \\
\left(\mathrm{mL} \mathrm{g}^{-1}\right)\end{array}$ & $\begin{array}{c}\text { APG } \\
\left(\mathrm{U} \mathrm{g}^{-1}\right)\end{array}$ \\
\hline 1 & $-1(50)$ & $-1(15)$ & $-1(5: 1)$ & 25,92 \\
\hline 2 & $+1(150)$ & $-1(15)$ & $-1(5: 1)$ & 24,59 \\
\hline 3 & $-1(50)$ & $+1(45)$ & $-1(5: 1)$ & 26,97 \\
\hline 4 & $+1(150)$ & $+1(45)$ & $-1(5: 1)$ & 26,68 \\
\hline 5 & $-1(50)$ & $-1(15)$ & $+1(10: 1)$ & 44,42 \\
\hline 6 & $+1(150)$ & $-1(15)$ & $+1(10: 1)$ & 48,60 \\
\hline 7 & $-1(50)$ & $+1(45)$ & $+1(10: 1)$ & 53,70 \\
\hline 8 & $+1(150)$ & $+1(45)$ & $+1(10: 1)$ & 38,39 \\
\hline 9 & $0(100)$ & $0(30)$ & $0(7,5: 1)$ & 36,10 \\
\hline 10 & $0(100)$ & $0(30)$ & $0(7,5: 1)$ & 34,62 \\
\hline 11 & $0(100)$ & $0(30)$ & $0(7,5: 1)$ & 39,58 \\
\hline
\end{tabular}

AG - agitação do meio; TC - tempo de contato entre o solvente e o meio fermentado; RE - relação solvente/massa; APG - atividade da poligalacturonase

Os resultados variaram de 24,59 a 53,70 $\mathrm{U} \mathrm{g}^{-1}$, sendo que o valor médio de atividade nos pontos centrais (ensaios $9,10,11$ ) foi de $36,76 \mathrm{U} \mathrm{g}^{-1}$; portanto, os maiores valores de atividade foram obtidos para $\mathrm{RE}=10: 1$ que apresentaram, em média, atividades de 48,9 $\mathrm{U} \mathrm{g}^{-1}$, contra a média de 25,83 para $\mathrm{RE}=5: 1$. Singh et al. (1999) avaliaram a influência da razão solvente/ massa na recuperação de pectinase de A. carbonarius, oscilando a razão entre 5 e 15 e concluíram que a melhor condição de extração foi a razão 10:1.

Os valores de atividade obtidos foram superiores aos encontrados por Souza et al. (2010), que obtiveram extratos enzimáticos com atividade poligalacturonásica de $20,9 \mathrm{U} \mathrm{g}^{-1}$ conduzindo a fermentação com os mesmos parâmetros da realizada neste trabalho utilizando, porém, outro método de extração que consistia em se adicionar $5 \mathrm{~mL}$ do tampão para cada grama de meio fermentado deixando o erlenmeyer em banho-maria, sem agitação, a $35^{\circ} \mathrm{C}$ por $1 \mathrm{~h}$, filtrando-o em seguida. Valores semelhantes aos de Souza et al. (2010) foram obtidos usando-se menores valores de RE (5:1), o que comprova a boa reprodutibilidade do processo fermentativo. Santos et al. (2008a), trabalhando com as mesmas condições de Souza et al. (2010) mas usando pedúnculo de caju como substrato, obtiveram aproximadamente $16 \mathrm{U} \mathrm{g}^{-1}$ de APG. Pinto et al. (2006), estudando a produção de poligalacturonase a partir da fermentação semissólida de casca de maracujá, obtiveram atividade de $21,85 \mathrm{U} \mathrm{g}^{-1}$ em condições de fermentação e extração diferentes das utilizadas neste trabalho.

Utilizando a ferramenta de planejamento experimental e a análise de superfície de resposta foi possível investigar a influência de determinadas variáveis em um processo e a forma de interação entre essas variáveis tal como, também, obter o valor das variáveis que maximizem os resultados esperados (Barros Neto \& Scarmínio, 1996).

Por meio do planejamento fatorial e da análise de superfície de resposta, verificou-se a influência das três variáveis de entrada, AG, TC e RE, sobre os valores da resposta APG, nos extratos obtidos.

Com os resultados de APG de cada ensaio foi possível se obter uma equação mediante regressão linear dos dados que relacionam a APG com os parâmetros estudados (Tabela 2).

Tabela 2. Análise de variância ANOVA

\begin{tabular}{ccr}
\hline Fonte de variação & SQ & GL \\
Regressão & 819,33 & 1 \\
Resíduo & 143,274 & 9 \\
Total & 962,6242 & 10 \\
$\mathrm{R}^{2}$ & 0,85114 & \\
$\mathrm{~F}_{\text {tabelado }}$ & 5,117 & \\
$\mathrm{~F}_{\text {calculado }}$ & 51,46032 & \\
Teste $\mathrm{F}$ & 10,5 & \\
\hline
\end{tabular}

A Eq.1 apresenta o modelo de regressão e os respectivos coeficientes de determinação para os dados de atividade poligalacturonásica obtidos.

$\mathrm{APG}=36,33+10,12 \mathrm{RE}+0,275 \mathrm{TC}-1,59 \mathrm{AG} \quad \mathrm{R}^{2}=0,87$

O coeficiente de determinação $\left(\mathrm{R}^{2}\right)$ quantificou a qualidade do ajuste pois fornece uma medida da proporção da variação explicada pela equação de regressão em relação à variação total das respostas.

Por meio do diagrama de Pareto (que apresenta, de forma rápida e clara, os efeitos estatisticamente importantes, considerando os efeitos cujos retângulos estiverem à direita da linha divisória) verificou-se, para o modelo de atividade da poligalacturonase, que o único efeito significativo é RE (Figura 1).

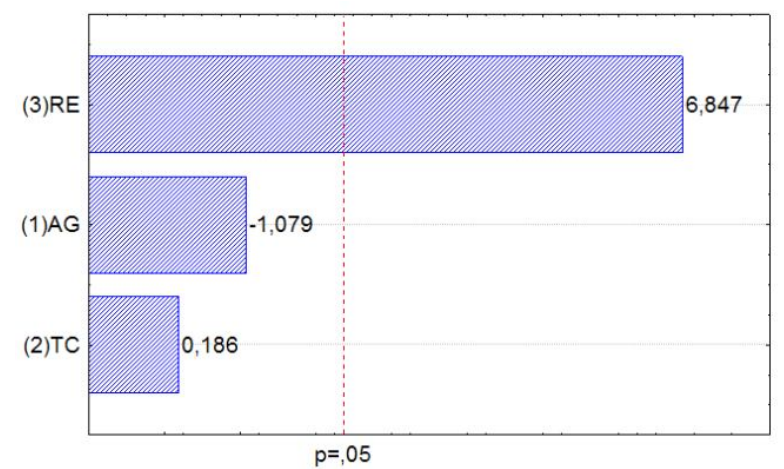

AG - agitação do meio; TC - tempo de contato entre o solvente e o meio fermentado; RE - relação solvente/massa

Figura 1. Diagrama de Pareto mostrando os efeitos estimados

Neste caso, a retirada de outros efeitos de menor valor contribui para um ajuste melhor do modelo, exibido na Eq. 2.

$$
\mathrm{APG}=36,33+10,12 \mathrm{RE} \quad \mathrm{R}^{2}=0,85
$$


A.

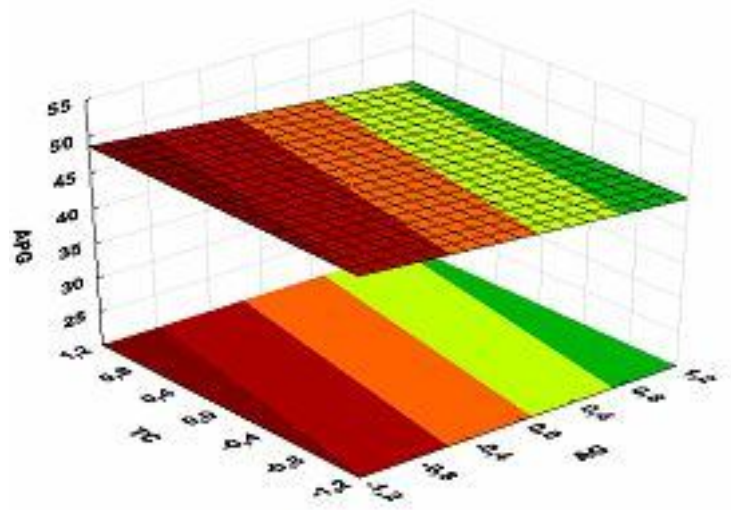

B.
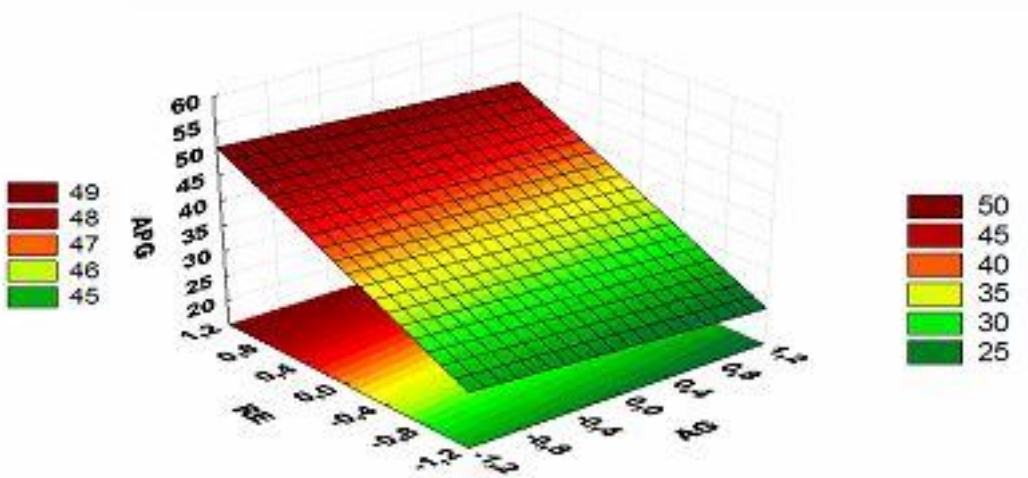

C.

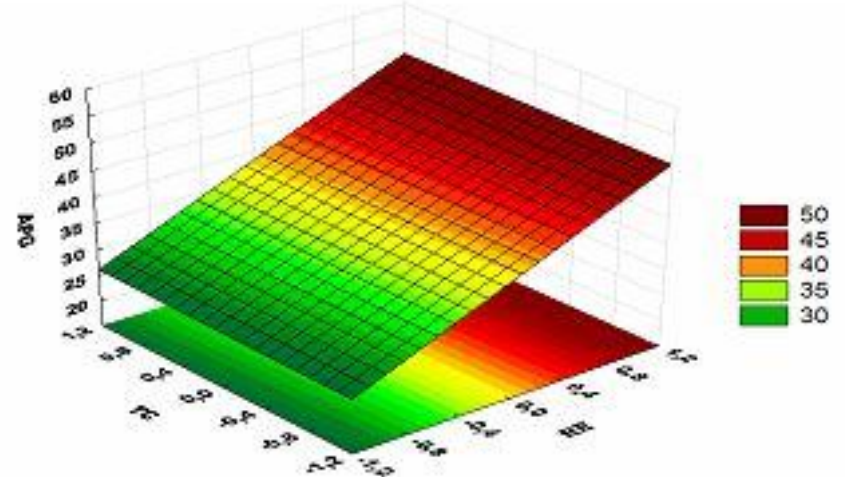

Figura 2. Influência do tempo de contato entre o solvente e o meio fermentado (TC) e agitação (AG) na atividade da poligalacturonase (APG) dos extratos, com relação solvente/massa (RE) fixado no nível + 1 (A); influência de RE e AG na APG dos extratos, com TC fixado no nível 0 (B); influência de RE e TC na APG dos extratos, com AG fixado no nível -1

A Tabela 2 apresenta a análise de variância ANOVA para APG e ainda exibe o resultado do Teste F, o qual representa a razão entre o F calculado e o F tabelado. Sempre que esta relação for maior que 1 a regressão será estatisticamente significativa havendo relação entre as variáveis independentes e as dependentes. Para que uma regressão não seja apenas estatisticamente significativa mas também útil para fins preditivos, o valor da razão deve ser no mínimo maior que 4,0 (Barros Neto \& Scarmínio, 1996).

Como o valor do teste $\mathrm{F}\left(\mathrm{F}_{\text {calculado }} / \mathrm{F}_{\text {tabelado }}\right)$ exibido na Tabela 2 é superior a 4,0, conclui-se que o modelo, além de estatisticamente significativo, também é preditivo; portanto, o modelo pode ser usado para predizer ou controlar o valor de APG mediante variação da RE, pelo menos na faixa dos valores testados.

As superfícies de resposta exibidas na Figura 2, foram construídas de forma a representar a influência das três variáveis estudadas no processo de extração (TC, AG, RE) na atividade poligalacturonásica do extrato (APG). A superfície de resposta é a descrição gráfica do modelo, o que simplifica a interpretação dos resultados.

A Figura 2A mostra a influência de TC e AG na atividade poligalacturonásica dos extratos obtidos (com RE fixado no nível +1). Verifica-se que nenhuma das variáveis tem influência significativa na atividade, principalmente a variável TC. Quanto à agitação $(\mathrm{AG})$, valores menores com maiores tempos de contato podem resultar em maior APG.
A Figura 2B exibe a influência de RE e AG na APG (com TC fixado no nível 0). Este gráfico não só confirma as discussões anteriores de que a variável que mais influencia no valor da APG é RE mas também mostra que valores menores de agitação contribuem para uma atividade ligeiramente maior. É possível que altos valores de AG causem desnaturação das enzimas diminuindo, assim, a presença de enzimas ativas e, em consequência, a atividade nos extratos.

A Figura 2C exibe a influência de RE e TC na APG (com AG fixado no nível -1); novamente se percebe forte influência de RE na atividade dos extratos e se verifica, portanto, que o tempo de contato (TC) praticamente não influi nos valores de atividade.

\section{Conclusões}

1. A variação dos parâmetros da lixiviação promoveu aumento de unidades de atividade enzimática recuperadas nos extratos obtidos.

2. Foram estabelecidos, como condição adequada para a recuperação de poligalacturonases do meio semissólido fermentado, o tempo de contato de $45 \mathrm{~min}$, agitação de $50 \mathrm{rpm}$ e a relação solvente/massa de 10:1 $\mathrm{mL} \mathrm{g}^{-1}$.

3. Dentre as variáveis estudadas no processo extrativo a relação solvente/massa (RE) foi o parâmetro que mais influenciou na atividade dos extratos. 
4. O modelo obtido mostrou-se, além de significativo, preditivo, podendo ser utilizado para predizer o valor da atividade poligalacturonásica recuperada nos extratos, mediante variação da relação solvente/massa na lixiviação.

\section{Agradecimentos}

Ao CNPq, pelo apoio financeiro.

\section{LITERATURA CITADA}

Alcântara, S. R.; Almeida, F. de A. C.; Silva, F. L. H. da. Pectinases production by solid state fermentation with cashew apple bagasse: Water activity and nitrogen source. Chemical Engineering Transactions, v.20, p.121-126, 2010.

Barros Neto, B.; Scarmínio, I. S.; Bruns, R. E. Planejamento e otimização de experimentos. 2.ed. Campinas: UNICAMP, 1996. 299p.

Camargo, L. A.; Dentillo, D. B.; Cardello, L.; Gattás, E. A. L. Utilização de bagaço de laranja na produção de pectinases de aspergillus sp. Alimentos e Nutrição, v.16, p.153-156, 2005.

Castilho. L. R.: Medronho. R. A.: Alves. T. L. M. Production and extraction of pectinases obtained by SSF of agroindustrial residues with Aspergillus niger. Bioresource Technology, v.71, p.45-50, 2000.

Couri, S.; Farias, A. X. Genetic manipulation of Aspergillus niger for increased synthesis of pectinolytic enzymes. Revista de Microbiologia, v.26, p.314-317, 1995.

Fernández, D. E. R. Desenvolvimento de um bioprocesso por fermentação e em estado sólido para produzir e recuperar enzimas de interesse comercial. Curitiba: UFPR, 2009. 125p. Tese Doutorado
Pinto, G.A. S.; Brito, E. S.; Silva, F. L. H. da; Santos, S. F. M.; Macedo, G. R. Fermentação em estado sólido: uma alternativa para o aproveitamento valorização de resíduos agroindustriais. Revista de Química Industrial, v.74, p.17-20, 2006.

Santos, S. F. M.; Macedo, G. R.; Silva, F. L. H. da; Souza, R. L. A.; Pinto, G. A. S. Aplicação da metodologia de superfície de resposta no estudo da produção e extração da poligalacturonase. Química Nova, v.31, p.1973-1978, 2008a.

Santos, S. F. M.; Souza, R. L. A.; Alcântara, S. R.; Pinto, G. A. S.; Silva, F. L. H. da; Macedo, G. R.; Aplicação da metodologia de superfície de resposta no estudo da produção de pectinase por fermentação em estado sólido do pedúnculo de caju. Revista Brasileira de Produtos Agroindustriais, v.10, p.101-109, 2008b.

Silva, D.; Tokuioshi, K.; Martins, E. S.; da Silva, R.; Gomes, E. Production of pectinase by solid-state fermentation with Penicillium viridicatum RFC3. Process Biochemistry, v.40, p.2885-2889, 2005.

Singh, S. A.; Ramakrishna, M.; Appu Rao, A. G. Optimization of ownstream processing parameters for the recovery of pectinase from the fermented bran of Aspergillus carbonarius. Process Biochemistry, v.35, p.411-417, 1999.

Sousa, C. A. B. Recuperação de poligalacturonases produzidas pela fermentação semi-sólida do resíduo agrícola do maracujá amarelo empregando sistema aquoso bifásico. Campina Grande: UFCG, 2010. 97p. Dissertação Mestrado

Souza, R. L. A.; Conrado, L.S.; Silva, F. L. H. da.; Amorim, B. C. Caracterização da poligalacturonase produzida por fermentação semi-sólida utilizando-se resíduo do maracujá como substrato. Revista Brasileira de Engenharia Agrícola e Ambiental, v.14, p.987-992, 2010.

Uenojo, M.; Pastore, G. M. Pectinases: Aplicações industriais e perspectivas. Química Nova, v.30, p.388-394, 2007.

Ustok, F. I.; Tari, C.; Gogus, N. Solid-stat production of polygalacturonase by Aspergillus sojae ATCC 20235. Journal of Biotechnology, v.127, p.322-334, 2007. 